\title{
Content of Vignettes and Ethical Sensitivity in Decision-Making: Case of Undergraduate Business Education Learners at University of Nairobi, Kenya
}

\author{
Prisca Mary Oluoch*, Paul Amollo Odundo, John Kamau Mwangi \\ Department of Educational Communication \& Technology, University of Nairobi, Nairobi, Kenya \\ Email address: \\ prioluoch@gmail.com(P.M. Oluoch), odundopaul@yahoo.com(P.A. Odundo),jmkamau@uonbi.ac.ke(J.K. Mwangi) \\ ${ }^{*}$ Corresponding author
}

To cite this article:

Prisca Mary Oluoch, Paul Amollo Odundo, John Kamau Mwangi. Content of Vignettes and Ethical Sensitivity in Decision-Making: Case of Undergraduate Business Education Learners at University of Nairobi, Kenya. Teacher Education and Curriculum Studies.

Vol. 5, No. 3, 2020, pp. 66-80. doi: 10.11648/j.tecs.20200503.15

Received: May 31, 2020; Accepted: June 19, 2020; Published: July 4, 2020

\begin{abstract}
Vignettes are instructional resources for experiential learning, which have been applied to train professionals in health sciences. Vignettes positively influence learning outcomes, learners' perceptions, as well as ethical sensitivity in decision-making by promoting higher order thinking skills. At the University of Nairobi's Department of Educational Communication and Technology, most instructors remain slow to embrace experiential learning and are inconsistent in applying vignettes in business ethics unit courses. This study examined the relationship between the use of vignettes and learners' ethical sensitivity in decision-making at the Department. The article focuses on content of vignettes. Cross-sectional survey design guided the research process, and data were collected from 116 learners at the University of Nairobi in 2018. The study required quantitative data to assess learners' perceptions on ethically sensitive issues, as well as qualitative data from interviews and focus group discussions. Results show vignettes derived from personal experiences, interviews and case studies were key influencers of learners' ethical sensitivity in decision-making. The study concludes that the more learners appreciate the relationship between vignette content and ethical sensitivity in decision-making, the stronger the odds of making ethical decisions and vice versa. Inclusion of vignettes derived from the cited contents as an instructional approach is likely to improve the probability of learners making ethically sensitive decisions.
\end{abstract}

Keywords: Content, Vignettes, Ethical Sensitivity, Decision-making, Business Education, Business Ethics

\section{Introduction}

Experiential learning refers to a unique set of instructional methods that can be deployed to develop the capacity of learners, using real life experiences. Authors such as [23, 4] and [41] appreciate that experiential learning is deeper and more complex than longstanding classical instructional methods such as lectures. Whereas classical instructional methods transmit abstract information, which most learners struggle to understand, experiential learning relies on practical experiences to enable learners to conceptualize new information, tandem with developing essential life skills [4] and ethical sensitivity, which are critical for decision-making at every decision point of the experiential learning cycle. This is possible because experiential learning methods create room for learners to think, reflect, share experiences and engage with peers and instructors, as well as apply newlyacquired skills to tackle similar challenges in their life [4, 41].

Vignettes are an instructional approach through which the stages of experiential learning can be operationalized in a teaching-learning process. Use of vignettes, particularly for undergraduate learners is appropriate since they are short scenarios that depict real-life illustrations brought into classroom situation with a single focus on ethical sensitivity to elicit decision-making. Vignettes influence learning outcomes, learners' perceptions about real life issues, as well as foster critical thinking, problem solving and ethical sensitivity in decision-making skills. [22] elucidate that vignettes create a vital linkage between learners' life 
experiences and the learning process, which helps to bridge theory and practice. On his part, [45] observe that vignettes provide a useful focus that helps learners to reflect upon lesson content, while addressing difficult-to-explore issues in real life situations. In an earlier study, [26] associated the use of vignettes in experiential learning with improvement in a culture of creativity and integrity since they promote reflection, engagement by learners through discussion and listening skills drawn from hearing and accommodating different perspectives within work groups. Further, [14] amplify the importance of vignettes in enhancing learners' ability to make ethical decisions in all facets of life, while [37] recognize vignettes for developing learners' ethical sensitivity in decision-making at various decision points encountered during the teaching-learning process. Besides, [27] appreciates vignettes for influencing learners' perceptions about real life experiences, and improving ethical sensitivity, which according to [39] is fundamental to decision-making.

Vignettes have been applied to train professionals in various fields, including medicine, nursing and psychology, as well as business management and marketing [1, 15]. However, little application has been made at the University of Nairobi (UoN) to institute the use of vignettes in teacher training. The Department of Educational Communication and Technology (hereafter referred to as 'the Department') at UoN, offers business education course under the Bachelor of Education (Arts), with one of the core units being business ethics [46]. The unit was designed to develop learners' ethical sensitivity, improve their ethical decision-making skills, and make them more resilient to challenges around ethical decision-making at the workplace. [35] as well as [38] identify classical instruction as the predominant learning model at the UoN, with its key features being scripted lesson plans, lectures, notes, passive involvement of learners and summative evaluations, which according to [18], depict salient attributes of instructor-centered learning.

In a study [44] suggests that the effectiveness of instructional methods depends on the ability to actively involve learners, capture their interests, influence perceptions and optimize learning outcomes. In an earlier study, [17] also assert that learner-centred strategies and methods of teaching have a great influence on learning outcomes and learner achievement. Based on this, one may validly deduce that predominant instructional methods at the UoN fail to meet the qualities of effective instructional methods. Nonetheless, [37] as well as [35] implicitly suggest that pedagogical reforms from instructor-centered learning models to learnercentered models have been underway in the institution's various academic units, including the Department. Despite this, anecdotal information shows that most instructors at the Department have been either slow in embracing experiential learning or inconsistent in applying vignettes to deliver business ethics lessons. Pertinent literature associates the challenge to inadequate knowledge about experiential learning, as well as the potential of vignettes in shaping learners' ethical sensitivity in decision-making skills [37].
Similarly, [36] indicate that inadequate preparation of instructors for experiential learning is one the factors preventing consistent application of vignettes to deliver the business ethics unit course, with far-reaching consequences on the ethical sensitivity in decision-making skills of the graduates.

Although vignettes have been used to train professionals in various fields, in the education sector, paucity of academic literature focusing on their use and ethical sensitivity in decision-making of learners, is a striking issue to education researchers, practitioners and policy experts [37, 36]. This study responded to the cited information gaps by assessing the influence of vignettes on ethical sensitivity in decisionmaking among business education undergraduate learners at the UoN. Even though the study covered five dimensions of vignettes, namely context, content, types, construction and utilization, this article delves into the relationship between the content of vignettes and ethical sensitivity in decisionmaking among university level teacher trainee learners. The findings should synergize pedagogical reforms, not only at the Department, but also in other academic units within the UoN. The findings should also influence further academic research on the subject in Kenya and other developing countries.

\section{Literature Review}

The deployment of effective instructional methods and resources marks the onset of developing ethically sensitive business managers and teachers. Vignettes are instructional resources that enhance the quality of learning by preexposing learners to real life experiences [22] typical of what they would find in their work places and presenting the kind of decision points they are likely to encounter later as employees or self-employed citizens. [20] as well as [32] identify several contents of vignettes, including role-plays, newspaper article reviews, songs, case studies, presentations, journals, diaries, debates, and textbooks, case studies and personal experiences. This study covered five of the contents of vignettes, viz. case studies, interviews, stories, textbook extracts and personal experiences. This section strives to highlight findings of previous studies, which show evidence of linkage between each content source of vignettes and learners' ethical sensitivity in decision-making.

[18] reports some linkage between case study vignettes and ethical sensitivity in decision-making, when he explains that case study vignettes provide learners with rich, in-depth knowledge about the subject matter, which, in turn, enhances awareness, knowledge and ethical sensitivity. [39] in an earlier study perceive ethical sensitivity as an essential antecedent to ethical decision-making. [28] associates learners' interactive engagement with case study vignettes and changes in the level of ethical sensitivity in decisionmaking. In this regard, case study vignettes enable learners to understand the importance of ethical decisions in future work environments including classroom situations. [31] also report some connection between case study vignettes and active 
involvement of learners in the teaching-learning process, which is essential for the retention of information about ethical sensitivity in decision-making. [37] also appreciate the usefulness of case study vignettes in shaping learners' ethical sensitivity and ethical decision-making proclivities. Arguably, such vignettes provide a learning framework that is enjoyable and enables learners to develop skills for making ethically sensitive decisions at various decision points whenever they present themselves. It further awakens the need to always incorporate ethical dimensions in decisionmaking, which is atypical of business environments, where the predominant focus in decision-making is exclusively on cost-benefit considerations. In a study on teaching ethics to undergraduate business students in Australia, which made a comparison of integrated and stand-alone approaches, [21] observe that case study vignettes enhance ethical sensitivity in decision-making of learners by exposing them to life experiences with ethical connotations. [16] assert that case study vignettes provide experiential frameworks, which enable learners to develop perspectives that facilitate ethical sensitivity in decision-making for better learning outcomes.

Information that connects interview vignettes and ethical sensitivity of learners in decision-making is scantily mentioned in a few studies. For example, [2] report that interview vignettes enable learners to probe difficult ethical dilemmas, from where ethical opinions are developed; while [11] aver that interview vignettes provide information that enable learners to actively construct new ideological opinions about real life experiences. In addition, [31] observe that interview vignettes provide information about experiences of practitioners, which is valuable for inferential learning and for improving the ability of learners to make ethically sensitive decisions.

The linkage between story vignettes and learners' ethical sensitivity in decision-making is another area that remains gray in terms of academic literature. Only a few studies have speculatively constructed some connection between the two aspects. For example, [39] explain that story vignettes create social learning atmospheres, which capture learners' attention, evoke their emotions and stimulate cognitive abilities necessary for ethical sensitivity in decision-making. On their part, [24] perceive a link between story vignettes and the improvement of learners' ethical ideologies; while [20] relate story vignettes with improvement in learners' critical thinking and ethical sensitivity. Similarly, Odundo \& Gunga [35] opine that personal perceptions developed through story vignettes can influence ethical ideologies of learners; while [40] argue that story vignettes expose learners to information on a wide range of virtues, including truthfulness, honesty and fairness, which form the basis for ethical sensitivity in decision-making.

Regarding vignettes extracted from textbooks, [3] explain that textbook vignettes have a direct link with business ethics course because they are extracted from course materials, which makes them effective in influencing ethical sensitivity of learners. Likewise, [42] observes that textbook vignettes relay information that is closely connected to course contents, which is critical for influencing ethical sensitivity. These views echo those expressed by [26] suggesting that textbook vignettes can systematically stimulate ethical sensitivity of learners and ethical ideologies for better learning outcomes and learner achievement. [7] also affirm that vignettes extracted from textbooks entail practical experiences that help learners to develop ethical ideologies. [10] relate textbook vignettes with improvement in learners' critical thinking and ethical ideologies, both of which give better outcomes in instances where sensitivity to decisionmaking is required. Critical thinking, ethical sensitivity and ethical ideologies are essential elements of ethical decisionmaking at any decision point during the teaching-learning process and in work situations.

Experiential learning requires learners to bring their personal experiences about a phenomenon into the learning process. The nexus between vignettes derived from personal experiences and ethical sensitivity in decision-making of learners are discernible in some studies. For example, [12] emphasize that personal experiences enhance ethical sensitivity; while [2] affirm that sharing personal experiences with peers is important for the development of ethical sensitivity and ethical decision-making skills. The authors observe that accommodating and learning from other people's experiences are crucial for influencing ethical sensitivity and for shaping ethical ideologies. When one is ethically sensitive, it is highly likely that they would demonstrate ethical principles when making decisions in different situations. In view of this, [11] hold that vignettes derived from personal experiences are likely to influence ethical reasoning and ethical sensitivity in decision-making of learners.

The literature review suggests that relationship between the content of vignettes and ethical decision-making among learners is a subject that has attracted a considerable number of studies, culminating in deductive as well as inductive conclusions. Despite this, the literature review reveals a dearth of statistical information that explicitly demonstrates that a causal relationship between the content of vignettes and learners' ethical sensitivity in decision-making skills or practices. Filling the cited information gap is what distinguishes this study from its predecessors.

The Experiential Learning Theory was applied to explain the process of human learning through experience, based on a set of six propositions. The theory holds that learning: is a continuous process and not an outcome; process is grounded on experience; requires resolution of conflicts between dialectically opposed modes of adaptation to the world; is a holistic process of adaptation; results from synergistic transactions between the learner and the environment; and is a process of creating knowledge [23, 30, 25] all of which lends itself as appropriate to business ethics education.

Experiential Learning Theory (ELT) encapsulates two interdependent conceptual features, namely, a four-stage learning cycle and a set of four learning styles, which collectively enhance its effectiveness in explaining experiential learning. The learning cycle concept holds that 
for experiential learning to occur, learners should develop through four stages, including concrete experience with a new situation; reflective observation of the situation; abstract conceptualization, which entail reflection; and active experimentation, which entails application of the new experience $[23,30]$. The experiential learning cycle integrates experience, reflection, conceptualization and action, which suggest that learning is perceived as an integrated process, revolving around the four stages [30]. Even though it is possible for experiential learning to begin at any stage of the cycle, effective learning can only occur when a learner is able to execute all the four stages [23] and is likely to encounter opportunities to make ethically sensitive decisions at each stage of the learning cycle. This implies that no single stage of the cycle can fully fulfill experiential learning on its own. The Theory further postulates that the experiential learning process is spiral, rather than linear. Under the linear model, learners are conditioned to become passive recipients of information; while the spiral model prepares learners for active participation in the learning process [23] and leads the them to go beyond knowledge acquisition to the testing of the acquired knowledge in action through reflection, and conceptualization and, thus, ensures much deeper knowledge transfer from theory to practice, from knowing to doing.

The four learning styles presented by Experiential Learning Theory are said to vary depending on the cognitive abilities of individual learners, and their interactions with the social environment [30]. However, it is debatable whether learners possess a single learning style for everything and at all times. The choice of teaching-learning styles adopted by instructors is further determined by the 'experiential learning style axes', including the processing continuum, which shows how learners approach learning tasks and the perception continuum, indicating learners' emotional response to experiential learning processes [23, 30]. Figure 1 shows the four learning styles, viz. diverging, assimilating, concrete experience and accommodating, as connected by the learning style axes.

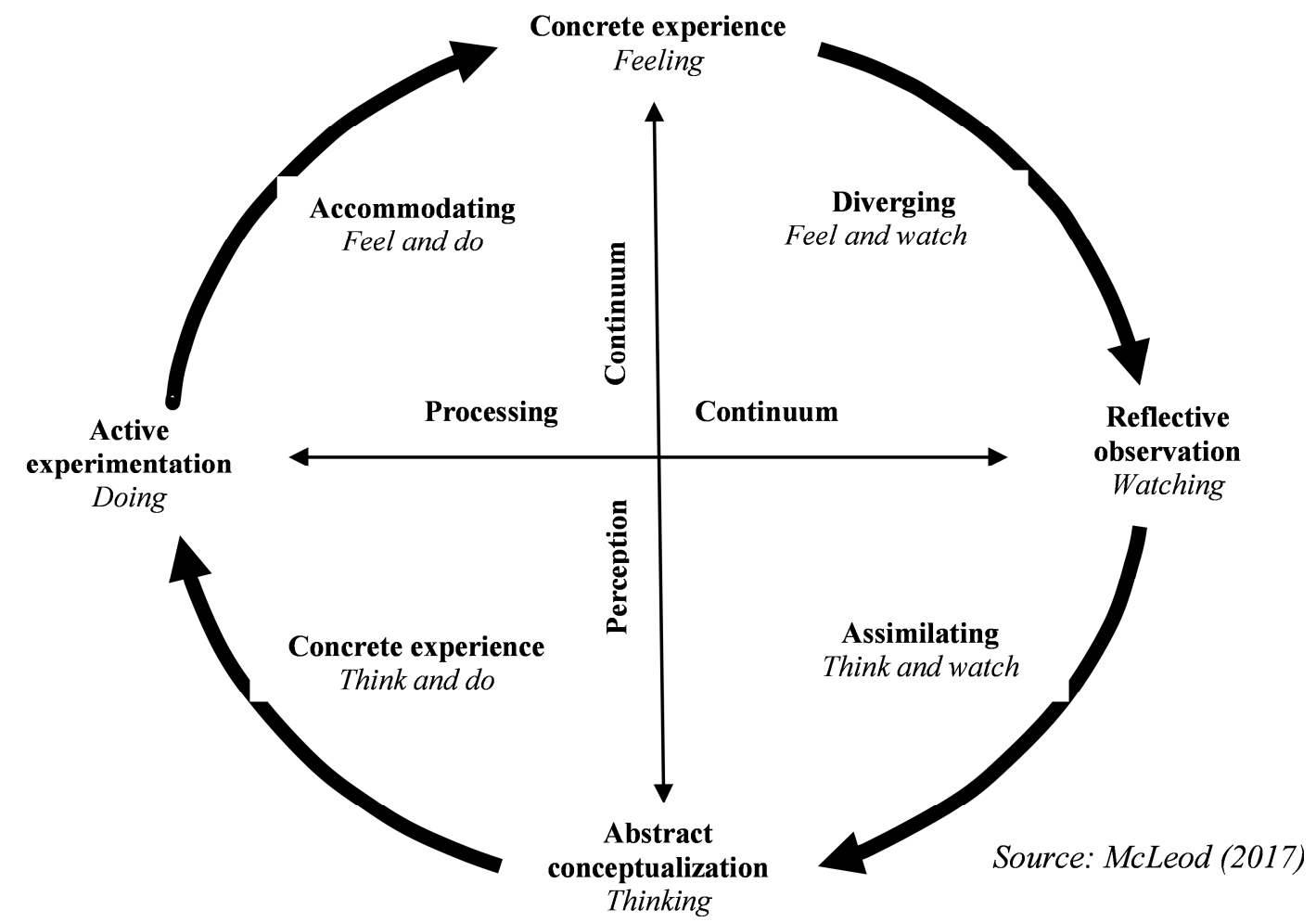

Figure 1. Experiential learning styles and learning axes.

Even though the learning styles are mutually interconnected, the theory sates that learners cannot perform both actions on a single axis at the same time since they will usually have one preference over the other. For example, it is believed that learners cannot prefer thinking and feeling in equal measure about the same thing at the same time, but can amalgamate actions inherent in two adjacent modes, such as thinking and watching, or thinking and doing, or feeling and watching or feeling and doing. What influences the choice of style, the personal preference in learning style itself, is actually the product of two pairs of variables, or two separate 'choices' that we make, which Kolb presented as lines of an axis, each with 'conflicting' modes at either end. The theory is relevant for this study because it explains how experiential learning keeps learners in touch with the reality being studied, thus distinguishing them from those who only read or write about reality [23]. Vignettes promote experiential learning by exposing learners to real-life experiences, which influence their ethical sensitivity, ideologies and decisionmaking skills. The use of vignettes subject learners to reallife experiences, which is essential for enabling learners to transform experience into knowledge and knowledge into new experiences. At the Department, the extent to which learners transform experiences into new knowledge depends 
on how well the business ethics module aligns with the Theory. Besides, it determines the extent to which learners develop their ethical sensitivity in decision-making while being aware of their preferred learning styles in different decision points.

The study examined the influence of vignettes and learners' ethical sensitivity in decision-making. However, this article focuses on how the content of vignettes influences ethical sensitivity in decision-making. In this regard, ethical sensitivity in decision-making was set as the dependent variable, with only two possible outcomes: ethically sensitive decisions or ethically insensitive decisions. The content of vignettes was set as the independent variable and measured in terms of five elements, namely, case studies, interviews, stories, textbook extracts and personal experiences. Figure 2 shows the hypothesized relationship between the content of vignettes and ethical sensitivity in decision-making.

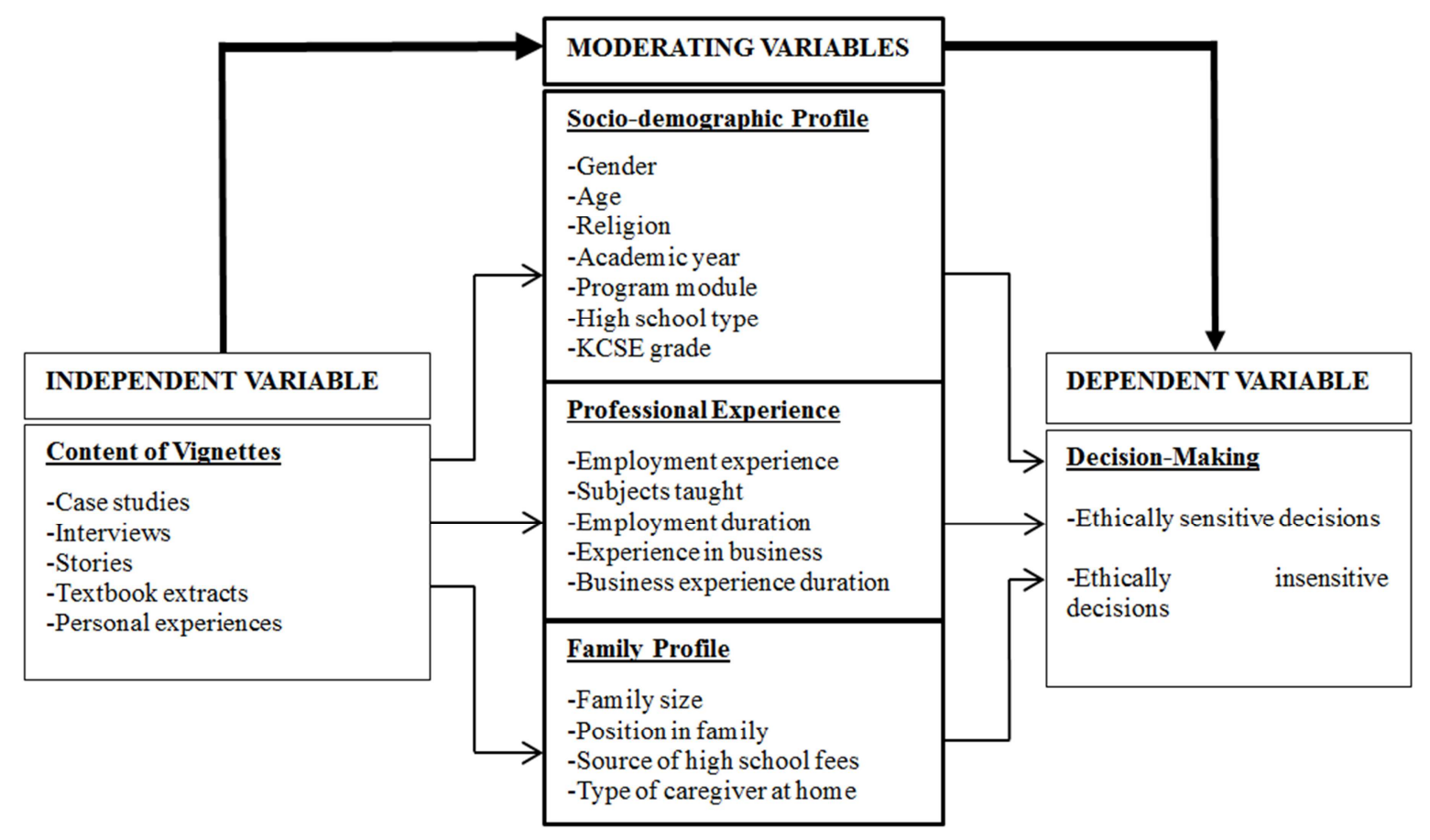

Figure 2. Hypothesized relationship between the content of vignettes and ethical sensitivity in decision-making.

Each content of vignettes was coined into a perception statement, which was measured using a five-point scale, calibrated as 'agree strongly', 'agree', 'undecided', 'disagree' and 'disagree strongly'. Participants were requested to indicate their views about each statement. The conceptual framework further shows that the relationship between the content of vignettes and ethical sensitivity in decision-making was moderated by three sets of factors, clustered as socio-demographic profile, professional experience and family profile of learners.

\section{Methodology}

The mixed methods approach was applied to source, process and analyze data; while the cross-sectional survey design guided the research process. The choice of the design was based on its ability to source both quantitative and qualitative information, cost-effectiveness, ability to minimize vulnerability to confounding factors by sourcing data at a single point in time, as well as the ability to generate a wide range of information using various measurement scales, including interval, nominal and ordinal $[43,6]$.

The targeted population included third- and fourth-year business education learners, as well as instructors of business education course unit at the Department. Management records indicated that there were 219 such learners at the time of the study, including 107 (48.9\%) in the third-year and $112(51.1 \%)$ in the fourth-year. Based on the management data, the sample size was computed using Cochran's formula [9].

$$
n i=\frac{Z^{2} p q}{d^{2}}=\frac{1.96^{2} \times 0.489 \times 0.511}{0.05^{2}}=383.97
$$

Where: $n_{i}=$ sample size, $Z=$ confidence level: $1.96, p=$ proportion of learners in the third-year: 0.489 and $q=$ proportion learners in the fourth-year (1-p): 0.511. The output was then adjusted for design effects using the correction factor indicated in formula 2: -

$$
n f=\frac{n i}{1+\frac{n i}{N i}}=\frac{383.97}{1+\frac{383.97}{219}}=139.46
$$

Where $n f=$ sample size correction factor, $n_{i}=$ computed sample size: $383.97, N_{i}=$ population: 219 . The correction process obtained a sample size of 139 learners. The sample size was divided proportionately between the two strata based on the population distribution, using formula 3 :

$$
n_{o}=f * s N_{o}
$$


Where $n_{o}=$ stratum sample size; $f=$ the sampling fraction $\left(n_{i} / N_{i}\right)$ and $s N_{o}=$ the stratum population (Kozak \& Zieli'nski, 2005). Further division of the computed sample size $\left(n_{i}\right)$ and the target population $\left(N_{i}\right)$ obtained a sampling fraction $(f)$ of 0.6368 . Using the sampling fraction, the computation yielded proportionate samples of 68 third- and 71 fourth-year learners. Stratified random sampling procedure was applied to sample learners; while instructors were sampled purposively. Primary data were sourced between May and November, 2018, using a self-administered questionnaire for learners, a Focus Group Discussion (FGD) guide for a second set of learners, and a Key Informant Interview (KII) guide for instructors. The tools and data sourcing approaches were pilot-tested between February and March, 2018 on secondyear learners at the Department.

Quantitative analysis involved cross-tabulation with Chisquare $\left(\chi^{2}\right)$ test of association, Spearman's Rank Correlation Coefficient, and Binary Logistic Regression (BLR) analysis $[48,33,34]$. BLR was applied to predict influence of the content of vignettes on learners' ethical decision-making, with two possible outcomes, viz. ethically sensitive decisions or ethically insensitive decisions. The model is expressed as indicated in formula (4):

$$
\begin{gathered}
\operatorname{Logit}[\theta(Y)]=\log \left[\frac{\theta(Y)}{1-\theta(Y)}\right]=\alpha+\beta_{1} X_{1}+\beta_{2} X_{2}+ \\
\beta_{3} X_{3} \ldots+\beta_{i} X_{i}+\varepsilon_{i}
\end{gathered}
$$

Where $Y=$ the predicted variable, in this case, ethical decision-making; $\theta(Y)=$ the probability of a learner making an ethically sensitive decision; $1-\theta(Y)=$ the probability of a learner making an ethically insensitive decision; $\alpha=$ constant term of the equation; $\beta_{1}, \beta_{2} \ldots \beta_{i}=$ regression coefficients; $X_{1}$, $X_{2} \ldots X_{i}=$ independent variables and $\varepsilon_{i}=$ the error term (Wuensch [48]). Although BLR yields various outputs, this article reports results interpreted from $\beta$ coefficients and odds ratios. The Statistical Package for Social Sciences and Microsoft Excel packages facilitated the quantitative analysis. More still, qualitative data were processed and analyzed following the three steps prescribed by [5]. Besides, the study complied with ethical principles of social science research, including respect for participants' rights to selfdetermination, voluntary participation and confidentiality [13].

\section{Results}

The results are presented under four sub-sections, including univariate analysis of ethical sensitivity in decision-making, bivariate analysis of the association between learners' background profile and ethical sensitivity in decision-making, bivariate analysis of the association between content of vignettes and ethical sensitivity in decision-making, and multivariate analysis of the content of vignettes and ethical sensitivity in decision-making.

\subsection{Univariate Analysis of Ethical Sensitivity in Decision- Making}

Learners were requested to read the hypothetical vignette presented below and make the most appropriate decision.

\begin{abstract}
You and Lisa are Business Education teachers at Kitenge High School, a mid-sized boys'baarding school. Your department has recently completed setting end of term examinations and the head of your department has handed it to you, with the request that you submit it to the examination office. You and Lisa are working late that night when you receive a call from the Principal, who asks you to immediately forward him a copy of the draft Business Echucation examination. When you locate the copy, you discover that your head of department had sealed it and written "Final Copy, Confidential" on the envelope. Your head of department is out of the country attending a seminar and you know it would be impossible to locate him for consultation. The Principal has a son in your class, who is always top of his class. How would you handle the Principal's request?
\end{abstract}

Figure 3. Hypothetical Vignette.

The purpose of the task was to enable the researchers to determine the proportion of learners whose decisions adhered to the principles underlying ethical sensitivity in decisionmaking, including taking ethical responsibility, acting with professionalism, maintaining confidentiality, upholding honesty and showing respect for legitimate authority [47]; [8]. The results presented in Table 1 show that of the 116 learners, $24(20.7 \%)$ took ethical responsibility in their decisions, while 34 (29.3\%) acted with professionalism.

Table 1. Proportion of learners' adhering to ethical sensitivity in decision-making principles.

\begin{tabular}{llllll}
\hline Principles guiding ethical & Yes & & No & Total \\
\cline { 2 - 6 } decision-making & Frequency & Percent & Frequency & Percent & Frequency \\
\hline Taking ethical responsibility & 24 & 20.7 & 92 & 79.3 & 116 \\
Acting with professionalism & 34 & 29.3 & 82 & 70.7 & 116 \\
Maintaining confidentiality & 51 & 44.0 & 65 & 56.0 & 116 \\
Upholding honesty & 14 & 12.1 & 102 & 87.9 & 100.0 \\
Showing respect for authority & 26 & 22.4 & 90 & 100.0 & 77.6 \\
\hline
\end{tabular}

Table 1 further shows that $51(44.0 \%)$ learners maintained confidentiality, 14 (12.1\%) upheld honesty, while $26(22.4 \%)$ showed respect for legitimate authority. Overall, most learners maintained confidentiality in their decisions, 51 (44.0); followed by those who acted professionally, 34 $(29.3 \%)$; while the least proportion of learners, 14 (12.1\%), 
upheld honesty. The results in Table 1 were aggregated to determine the proportion of learners who were ethically sensitive and those ethically insensitive in their decisions. In this regard, the analysis showed that on aggregate, 30 $(25.9 \%)$ learners made ethically sensitive decisions, while 86 (74.1\%) exhibited ethical insensitivity in their decisions.

\subsection{Bivariate Analysis of the Association between Ethical Sensitivity in Decision-Making and Learners' Profile}

The results in Table 2 show that learners involved in the study included $59(50.9 \%)$ males and 57 (49.1\%) females. Those who were ethically sensitive in their decisions $(n=30)$, included 17 (56.7\%) females and 13 (43.3\%) males; while those who were ethically insensitive $(n=86)$, consisted of 46 $(53.5 \%)$ males and $40(46.5 \%)$ females. However, the analysis revealed lack of a significant association between ethical sensitivity in decision-making and learners' gender $\left(\chi^{2}=0.556, \mathrm{df}=1 \& \rho\right.$-value $\left.=0.456\right)$. This suggests that the decisions made by male and female learners were homogenous in terms of ethical sensitivity, which presents a departure from several earlier studies, which reported higher ethical sensitivity in female learners than in male learners based on findings that, in general, women are more compliant than men. Other studies have also sought to explain differences in the behavioural patterns of men and women in ethical decision-making from the standpoint of gender orientation, whereby women are taught from an early age to defer to authority and tend to have a lower risk propensity than men [29]. This study found that female thinking in terms of beliefs and sensitivity on ethical issues is becoming closer to male beliefs and sensitivity to ethical issues, perhaps due to the fact that the learners have been exposed to similar experiences and modes of socialization. This finding is consistent with [29] earlier prediction that when it comes to ethical decision-making, differences between men and women will diminish as more women enter the work force and assume male positions.

Table 2. Learners' socio-demographic attributes and ethical sensitivity in decision-making.

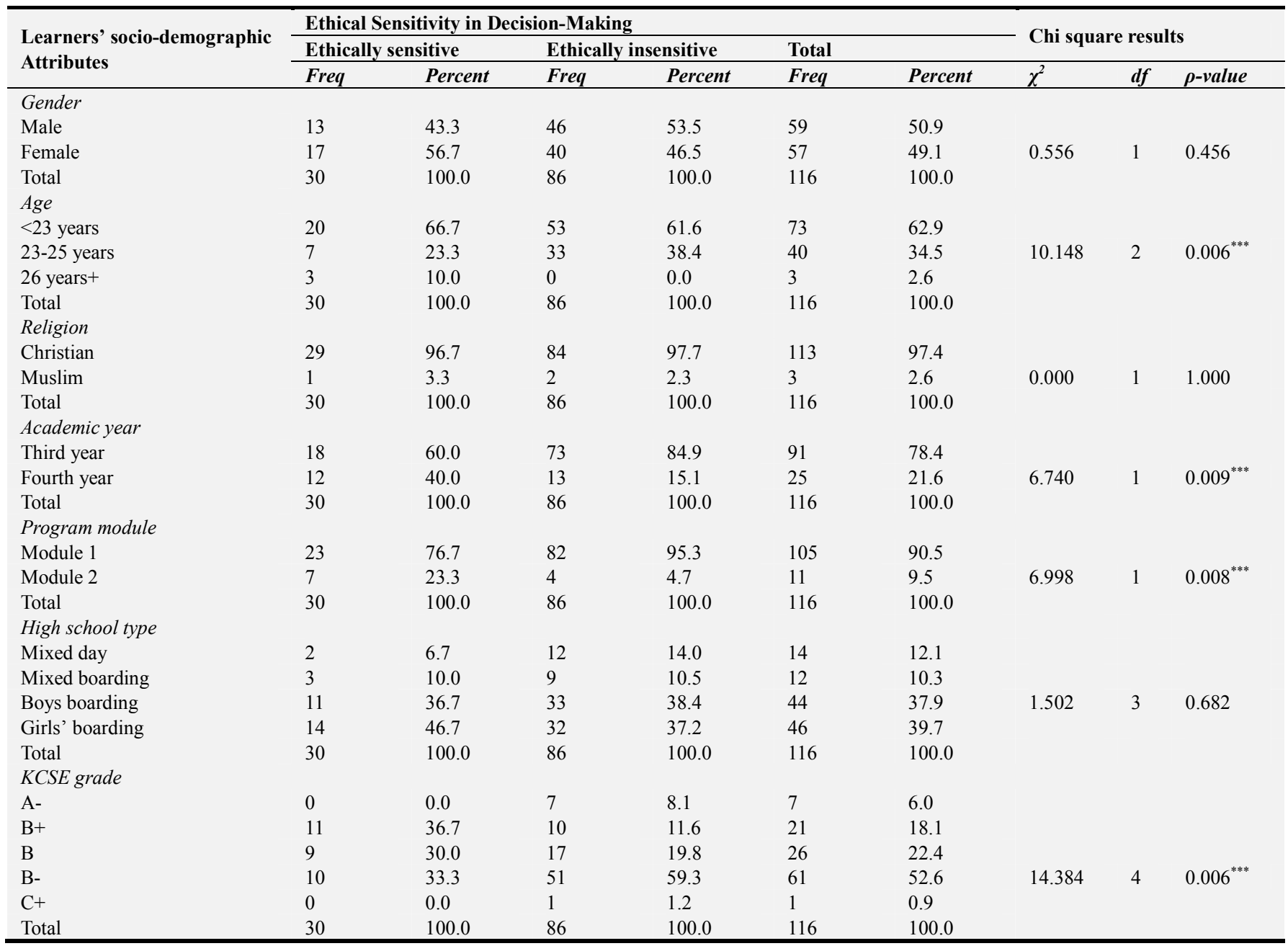

$*, * * * * *$ show significance at $\rho<0.1, \rho<0.05$ and $\rho<0.01$ error margins, respectively.

The study involved $73(61.6 \%)$ learners aged below 23 years and $40(34.5 \%)$ in the $23-25$ years age bracket, while 3 $(3.9 \%)$ were above 26 years old. Table 2 shows that those who were ethically sensitive $(n=30)$, included $20(66.7 \%)$ learners aged below 23 years, and $7(23.3 \%)$ in the $23-25$ years category. Those who were ethically insensitive $(n=86)$, 
comprised $53(61.6 \%)$ learners aged below 23 years, and 33 $(38.4 \%)$ in the $23-25$ years category. Based on this, the analysis revealed a significant association between ethical sensitivity in decision-making and learners' age $\left(\chi^{2}=10.148\right.$, $\mathrm{df}=2 \& \rho$-value $=0.006)$. This indicates that they lower age group showed less ethical sensitivity and hence ethical competence than the older age group in terms of their decision-making skills. This further suggests that there is a need to train learners to develop ethical competence and sensitivity in values in terms of how to handle ethical conflicts and dilemmas at the work place.

Of the 116 learners, 113 (97.4\%) were Christians, who also formed the majority of those who demonstrated ethical sensitivity, 29 (96.7\%); as well as those who were ethically insensitive, 84 (97.7\%). Despite this, the analysis revealed lack of a significant association between ethical sensitivity in decision-making and learners' religious affiliation $\left(\chi^{2}=\right.$ 0.000 , df $=1 \& \rho$-value $=1.000)$. This suggests that Christians and Muslims were homogenous in terms of level of ethical sensitivity and therefore the ability to recognize ethical problems in situations in order to make ethically sensitive decisions.

The results presented in Table 2 further indicate that 91 (78.4\%) learners were in third year, while $25(21.6 \%)$ were in fourth year. Among the 30 learners who made ethically sensitive decisions, $18(60.0 \%)$ were in third year, while 12 $(40.0 \%)$ were in fourth year. Those whose decisions were ethically insensitive $(n=86)$, consisted of $73(84.9 \%)$ learners in third year and $13(15.1 \%)$ in fourth year. The analysis revealed up to $99 \%$ chance that ethically sensitive decisionmaking significantly associated with learners' year of study $\left(\chi^{2}=10.255, \mathrm{df}=1 \& \rho\right.$-value $\left.=0.005\right)$. Of the 116 learners, $105(90.5 \%)$ were learning under module 1 or the regular program, while $11(9.5 \%)$ were in module 2 , dubbed the 'parallel program'. Those who demonstrated ethical sensitivity $(\mathrm{n}=30)$, included $23(76.7 \%)$ learners in module 1 , and $7(23.3 \%)$ in module 2 . Table 2 shows that among those who were ethically insensitive $(n=86), 82(95.3 \%)$ were in module 1 , while $4(4.7 \%)$ were in module 2 . The analysis revealed up to $99 \%$ chance that ethical sensitivity in decision-making significantly associated with learners' program of study $\left(\chi^{2}=6.998, \mathrm{df}=1 \& \rho\right.$-value $\left.=0.008\right)$. The learners in fourth year may have more experience in dealing with ethical dilemmas and therefore demonstrated more ethical sensitivity in decision-making than the younger third year teacher trainees.

The results in Table 2 also indicate that 46 (39.7\%) learners attended girls' boarding schools, 44 (37.9\%) indicated boys' boarding schools, while 14 (12.1\%) stated mixed day schools. In the category of 30 learners who demonstrated ethical sensitivity in decision-making, 14 (46.7\%) studied in girls' boarding schools, while 11 (36.7\%) went through boys' boarding schools. Those who exhibited ethical insensitivity $(\mathrm{n}=86)$, included $33(38.4 \%)$ learners who studied in boys' boarding, and 32 (37.2) who attended girls' boarding schools. Despite this, there was no significant association between ethical sensitivity in decision-making and the type of high school attended $\left(\chi^{2}=1.502, \mathrm{df}=3 \& \rho-\right.$ value $=1.682)$. Finally Table 2 reveals that $61(52.6 \%)$ learners attained grade B- in the Kenya Certificate of Secondary Education (KCSE), while 26 (22.4\%) reported a mean grade of $\mathrm{B}$. Among those who showed ethical sensitivity $(\mathrm{n}=30), 11(36.7 \%)$ attained $\mathrm{B}+$, while $10(33.3 \%)$ indicated B-. Among those who displayed ethical insensitivity ( $\mathrm{n}=86), 51(59.3 \%)$ achieved B-, while 10 (11.6\%) mentioned $\mathrm{B}+$. The association between ethical sensitivity in decision-making and the KCSE mean grade was significant at $99 \%$ confidence level $\left(\chi^{2}=14.384, \mathrm{df}=4 \& \rho\right.$ value $=0.006$ ) .

The results presented in Table 3 further show the Chi square test results between ethical sensitivity in decisionmaking and a number of variables encapsulated by learners' professional and family profiles. The results show that ethical sensitivity in decision-making significantly associated with all the variables constituting learners' professional profile, at three levels of confidence, viz. $90 \%, 95 \%$ and $99 \%$.

Table 3. Statistical association between ethical decision-making and learners' profiles.

\begin{tabular}{|c|c|c|c|c|}
\hline \multirow{2}{*}{ Learners' profile } & \multirow{2}{*}{ Variables } & \multicolumn{3}{|c|}{ Chi square results } \\
\hline & & $\chi^{2}$ & $d f$ & $\rho$-value \\
\hline \multirow[t]{5}{*}{ Professional } & Employment experience & 5.446 & 1 & $0.020^{* * *}$ \\
\hline & Subjects taught & 12.734 & 7 & $0.079^{*}$ \\
\hline & Employment duration & 9.886 & 2 & $0.007^{* * *}$ \\
\hline & Experience in business & 6.981 & 1 & $0.008^{* * *}$ \\
\hline & Business experience duration & 5.355 & 2 & $0.024^{* *}$ \\
\hline \multirow[t]{4}{*}{ Family } & Family size & 0.222 & 2 & 0.895 \\
\hline & Position in family/birth order & 7.031 & 2 & $0.030^{* *}$ \\
\hline & Source of high school fees & 4.999 & 4 & 0.287 \\
\hline & Type of caregiver at home & 4.248 & 3 & 0.236 \\
\hline
\end{tabular}

$*, * *, * * *$ show significance at $\rho<0.1, \rho<0.05$ and $\rho<0.01$ error margins, respectively.

Concerning family profile, the results show that ethical sensitivity in decision-making is significantly associated with learners' position or birth order in the family. The attributes that did not show significant associations with ethical sensitivity in decision-making were excluded from multivariate analysis because they were less likely to add value. 


\subsection{Bivariate Analysis of the Association between the Content of Vignettes and Ethical Sensitivity in Decision-Making}

Each of the five contents of vignettes, namely, case studies, interviews, stories, textbook extracts and personal experiences, was transformed into a perception statement.
Learners were asked to indicate their views on a five-point Likert scale, graduated as 'agree strongly', 'agree', 'undecided', 'disagree' and 'disagree strongly'. Each perception statement was cross-tabulated with ethical sensitivity in decision-making to determine the statistical significance of association, and the results are summarized in Table 4.

Table 4. Learners' perceptions on the contents of vignettes and ethical sensitivity in decision-making.

\begin{tabular}{|c|c|c|c|c|c|c|c|c|c|}
\hline \multirow{3}{*}{ Contents of vignettes } & \multicolumn{6}{|c|}{ Ethical Sensitivity in Decision-Making } & \multirow{2}{*}{\multicolumn{3}{|c|}{ Chi square results }} \\
\hline & \multicolumn{2}{|c|}{ Ethically sensitive } & \multicolumn{2}{|c|}{ Ethically insensitive } & \multicolumn{2}{|l|}{ Total } & & & \\
\hline & Freq & Percent & Freq & Percent & Freq & Percent & $\chi^{2}$ & $d f$ & $\rho$-value \\
\hline \multicolumn{10}{|c|}{ Case studies provide learners with in-depth knowledge on ethical issues } \\
\hline Strongly agree & 16 & 53.3 & 50 & 58.1 & 66 & 56.9 & & & \\
\hline Agree & 7 & 23.3 & 29 & 33.7 & 36 & 31.0 & & & \\
\hline Undecided & 2 & 6.7 & 7 & 8.1 & 9 & 7.8 & 15.259 & 4 & $0.004^{* * *}$ \\
\hline Disagree & 2 & 6.7 & 0 & 0.0 & 2 & 1.7 & & & \\
\hline Total & 30 & 100.0 & 86 & 100.0 & 116 & 100.0 & & & \\
\hline \multicolumn{10}{|c|}{ Interviewing business practitioners instills ethical sensitivity in them } \\
\hline Strongly agree & 17 & 56.7 & 37 & 43.0 & 54 & 46.6 & & & \\
\hline Agree & 6 & 20.0 & 36 & 41.9 & 42 & 36.2 & & & \\
\hline Undecided & 1 & 3.3 & 5 & 5.8 & 6 & 5.2 & 9.955 & 4 & $0.041^{* *}$ \\
\hline Disagree & 1 & 3.3 & 5 & 5.8 & 6 & 5.2 & & & \\
\hline Strongly disagree & 5 & 16.7 & 3 & 3.5 & 8 & 6.9 & & & \\
\hline \multicolumn{10}{|c|}{ Stories enable learners to encounter practical business ethical dilemmas } \\
\hline Strongly agree & 11 & 36.7 & 24 & 27.9 & 35 & 30.2 & & & \\
\hline Agree & 8 & 26.7 & 31 & 36.0 & 39 & 33.6 & & & \\
\hline Undecided & 3 & 10.0 & 23 & 26.7 & 26 & 22.4 & & & \\
\hline Disagree & 3 & 10.0 & 4 & 4.7 & 7 & 6.0 & 9.123 & 4 & $0.058^{*}$ \\
\hline Strongly disagree & 5 & 16.7 & 4 & 4.7 & 9 & 7.8 & & & \\
\hline Total & 30 & 100.0 & 86 & 100.0 & 116 & 100.0 & & & \\
\hline \multicolumn{10}{|c|}{ Textbook extracts assist thought process in learning business ethics } \\
\hline Strongly agree & 10 & 33.3 & 38 & 44.2 & 48 & 41.4 & & & \\
\hline Agree & 11 & 36.7 & 32 & 37.2 & 43 & 37.1 & & & \\
\hline Undecided & 3 & 10.0 & 14 & 16.3 & 17 & 14.7 & 11.481 & 4 & $0.022^{* *}$ \\
\hline Disagree & 4 & 13.3 & 1 & 1.2 & 5 & 4.3 & & & \\
\hline Strongly disagree & 2 & 6.7 & 1 & 1.2 & 3 & 2.6 & & & \\
\hline Total & 30 & 100.0 & 86 & 100.0 & 116 & 100.0 & & & \\
\hline \multicolumn{10}{|c|}{ Personal experiences enhance business moral perception among learners } \\
\hline Strongly agree & 10 & 33.3 & 28 & 32.6 & 38 & 32.8 & & & \\
\hline Disagree & 3 & 10.0 & 0 & 0.0 & 3 & 2.6 & 12.128 & 4 & $0.016^{* *}$ \\
\hline Strongly disagree & 2 & 6.7 & 2 & 2.3 & 4 & 3.4 & & & \\
\hline Total & 30 & 100.0 & 86 & 100.0 & 116 & 100.0 & & & \\
\hline
\end{tabular}

$*$,**,*** show significance at $\rho<0.1, \rho<0.05$ and $\rho<0.01$ error margins, respectively.

The first statement posited that 'case studies provide learners with in-depth knowledge on ethical issues'. Table 4 shows that of the 116 participants, $66(56.9 \%)$ agreed strongly with the claim, $36(31.0 \%)$ agreed, while $3(2.6 \%)$ disagreed strongly. Cumulatively, $102 \quad(87.9 \%)$ learners endorsed the claim, while 5 (4.3\%) refuted it. Among the 30 learners who demonstrated ethical sensitivity in their decisions, $16(53.3 \%)$ agreed strongly with the statement, 7 (23.3\%) agreed, while $3(10.0 \%)$ disagreed strongly. Among those whose decisions were ethically insensitive $(n=86), 50$ (58.1\%) agreed strongly, while 29 (33.7\%) agreed. Based on this, the analysis generated a $\chi^{2}$ value of $15.259(\mathrm{df}=4 \& \rho=$ 0.004 ), which suggests that up to $99 \%$ chance that ethical sensitivity in decision-making significantly associated with the perception that case studies provide learners with indepth knowledge on ethical issues. This further suggests that the application of case study vignettes in business ethics lessons influenced learners' knowledge on ethical issues. The latter is a crucial forerunner to ethical sensitivity in decisionmaking.

The second statement postulated that interviewing business practitioners instills ethical sensitivity in learners'. Table 4 show that $54(46.6 \%)$ learners agreed strongly with the statement, $42(36.2 \%)$ agreed, $6(5.2 \%)$ disagreed, while $8(6.9 \%)$ disagreed strongly. Cumulatively, 96 (82.8\%) learners affirmed the assertion, while 14 (12.1\%) expressed contrary views. Among those whose decisions were ethically sensitive $(\mathrm{n}=30), 17(56.7 \%)$ agreed strongly with the 
statement, $6(20.0 \%)$ agreed, while $5(16.7 \%)$ disagreed strongly. Those who exhibited ethical insensitivity $(n=86)$, included $37(43.0 \%)$ learners who agreed strongly, 36 $(41.9 \%)$ agreed and $5(5.8 \%)$ who disagreed. The analysis revealed a significant statistical association between ethical sensitivity in decision-making and the perception claiming that interviewing business practitioners instills ethical sensitivity in them $\left(\chi^{2}=9.955, \mathrm{df}=4 \& \rho\right.$-value $\left.=0.014\right)$. This suggests up to $95 \%$ chance that applying interview vignettes is likely to influence learners' ethical sensitivity, which often precedes ethical decision-making.

Thirdly, learners indicated their views on the perception statement claiming that 'stories enable learners to encounter practical business ethical dilemmas'. Table 4 shows that 35 $(30.2 \%)$ learners agreed strongly with the claim, while 39 (33.6\%) agreed. Contrastingly, 7 (6.0\%) learners disagreed with the statement, while $9(7.8 \%)$ disagreed strongly. Collectively, $74(63.8 \%)$ learners affirmed the statement; only $16(13.8 \%)$ indicated dissention. In the category of learners who made ethically sensitive decisions $(n=30), 11$ $(36.7 \%)$ learners agreed strongly with the statement, 8 (26.7\%) agreed, while $5(16.7 \%)$ disagreed strongly. Those whose decisions were ethically insensitive $(\mathrm{n}=86)$, included $24(27.9 \%)$ who agreed strongly with the claim, $31(36.0 \%)$ who agreed and $4(4.7 \%)$ who disagreed. Based on this, the results suggested up to $90 \%$ chance that ethical sensitivity in decision-making significantly associated with the perception that stories enable learners to encounter practical business ethical dilemmas $\left(\chi^{2}=9.123, \mathrm{df}=4 \& \rho=0.058\right)$. This further suggests that the deployment of story vignettes in business ethics lessons is likely to influence learners' ethical sensitivity in decision-making.

The fourth statement asserted that 'textbook extracts assist thought process in learning business ethics'. The results in Table 4 indicate that $48(41.4 \%)$ learners agreed strongly

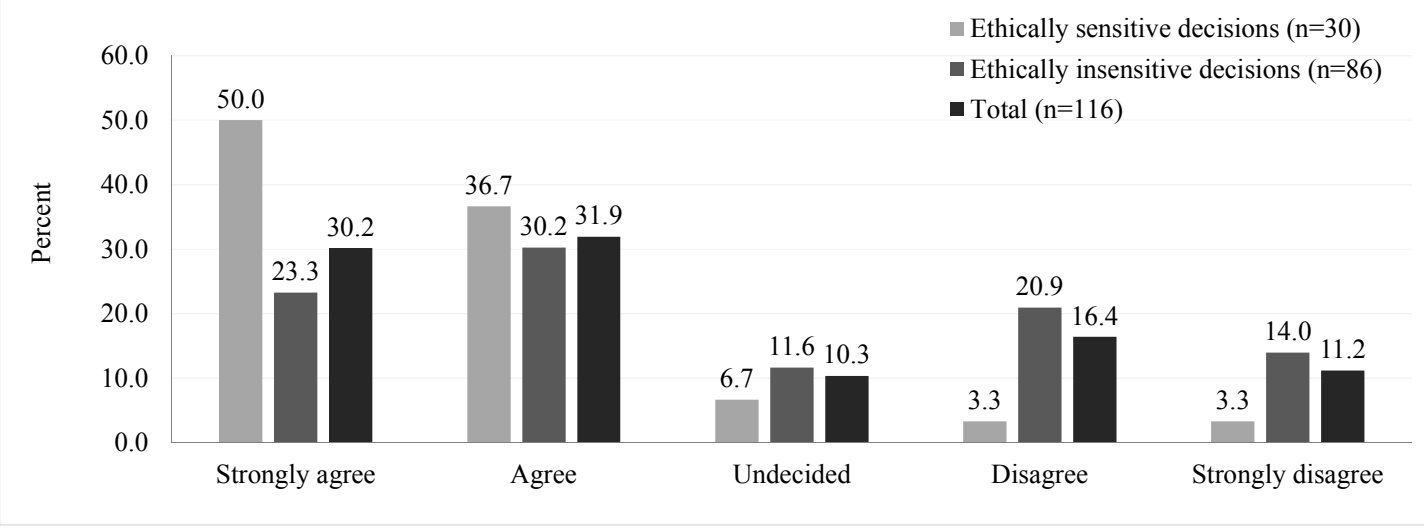

Figure 4. Aggregated views on the link between content of vignettes and ethical sensitivity in decision-making.

Learners' views about the five perception statements were aggregated to determine the optimal perception about the nexus between the content of vignettes and ethical decisionmaking. The results presented in Figure 4 show that of the 116 learners, 37 (31.9\%) agreed that the content of vignettes influences ethical sensitivity in decision-making, 35 (30.2\%) with the assertion, $43(37.1 \%)$ agreed, 5 (4.3\%) disagreed, while those who disagreed strongly were only $3(2.6 \%)$. Cumulatively, 91 (78.4\%), affirmed the assertion, while 8 (6.9\%) indicated opposing views. Among the 30 learners whose decisions were ethically sensitive, 10 (33.3\%) agreed strongly with the assertion, $11(36.7 \%)$ agreed, while 4 $(13.3 \%)$ disagreed. Among those who demonstrated ethical insensitivity $(\mathrm{n}=86), 38(44.2 \%)$ agreed strongly with the assertion, while $32(37.2 \%)$ agreed. The analysis revealed up to $95 \%$ chance that ethical sensitivity in decision-making and the perception holding that textbook extracts assist thought process in learning business ethics were significantly associated $\left(\chi^{2}=11.481\right.$, df $=4 \& \rho$-value $\left.=0.022\right)$. This further suggests that the application of vignettes extracted from textbooks is likely to influence learners' ethical sensitivity in decision-making.

The fifth statement purported that 'personal experiences enhance business moral perception among learners'. Table 4 indicates that $52(44.8 \%)$ learners agreed with the perception, $38(32.8 \%)$ agreed strongly, while $4(3.4 \%)$ indicated strong disagreement. Collectively, 90 (77.6\%) learners validated the perception, while $7(6.0 \%)$ invalidated it. Of the 30 learners whose decisions were ethically sensitive, 10 (33.3\%) agreed strongly with the perception, $9(30.0 \%)$ agreed, while $3(10.0 \%)$ disagreed. Among those whose decisions were ethically insensitive $(n=86), 43(50.0 \%)$ agreed with the perception, 28 (32.6\%) agreed strongly, while $2(2.3 \%)$ disagreed strongly. The analysis obtained a $\chi^{2}$ value of $12.128(\mathrm{df}=4 \& \rho=0.016)$, which suggests up to $95 \%$ chance that ethical sensitivity in decision-making significantly associated with the perception that personal experiences enhance business moral perception among learners. This further suggests that application of vignettes derived from personal experiences in business ethics lessons is likely to influence learners' ethical sensitivity in decision-making. agreed strongly, 19 (16.4\%) disagreed, while 13 (11.2\%) disagreed strongly. In the category of learners whose decisions were ethically sensitive $(n=30), 15$ (50.0\%) agreed strongly that vignettes' contents influence ethical sensitivity in decision-making, while $11(36.7 \%)$ agreed with the assertion. Among those who were ethically insensitive 
$(\mathrm{n}=86), 26(30.2 \%)$ agreed with the assertion connecting vignettes' contents and ethical sensitivity in decision-making, $20(23.3 \%)$ agreed strongly, while 18 (20.9\%) disagreed.

Based on the results in Figure 4, the analysis obtained a spearman's rank correlation coefficient $r_{\mathrm{s}}$ of 0.218 ( $\rho$-value $=$ 0.019 ); suggesting up to $95 \%$ chance that the contents of vignettes significantly correlate with learners' ethical sensitivity in decision-making. This prompted rejection of the null hypothesis stating that there is no significant correlation between the content of vignettes and ethical sensitivity in decision-making, for being inconsistent with the results.

\subsection{Influence of the Content of Vignette on Ethical Sensitivity in Decision-Making: Multivariate Analysis}

Bivariate results show that learners' aggregated perceptions about the content of vignettes significantly correlated learners' ethical sensitivity in decision-making. However, this did not tell the extent to which the content of vignettes influenced ethical sensitivity in decision-making. For this reason, the content of vignettes, alongside other independent variables, were regressed against learners' ethical sensitivity in decision-making (dependent variable). Learners' profile attributes were included in the regression model as moderating factors.

Collinearity diagnostics revealed a confounded relationship between learners' experience in business and duration of business experience. In this regard, duration of business experience was dropped from the regression model because it had a weaker effect on regression coefficients $(\beta)$, in accordance with the principles BLR (Wuensch [48]). Regarding Odds Ratios (OR), the results in Table 5 show that learners who agreed strongly that the content of vignettes influences their ethical sensitivity in decision-making had about 1.8 times the odds of making ethically sensitive decisions as their counterparts who disagreed strongly with the premise $(\rho$-value $=0.022, \beta=0.604, \mathrm{OR}=1.829, \mathrm{C} . \mathrm{I} .=$ $1.266-2.644$ ). The results suggest up to $95 \%$ chance that the two groups varied significantly in terms of ethical sensitivity in decision-making tendencies.

Table 5. Results of the adjusted logistic regression model.

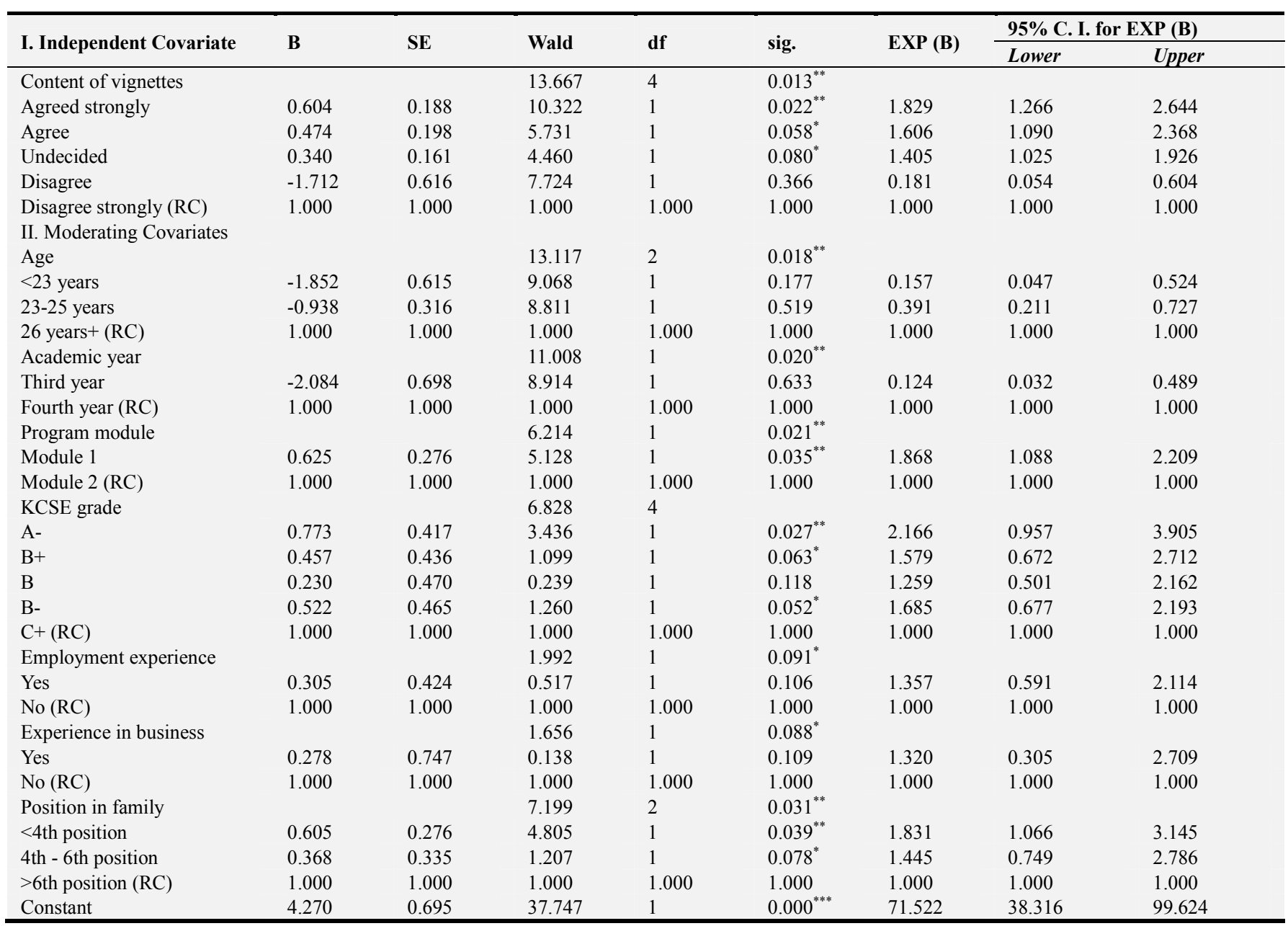

$*, * *, * * *$ show significance at $\rho<0.1, \rho<0.05$ and $\rho<0.01$ error margins, respectively.

$\mathrm{RC}=$ Reference Category.

Furthermore, learners who agreed that the content of vignettes influences their ethical sensitivity in decision- making were about 1.6 times as likely to make ethically sensitive decisions as their colleagues who indicated 
strong disagreement $(\rho$-value $=0.058, \beta=0.474, \mathrm{OR}=$ 1.606 , C. I. $=1.090-2.368)$. Again, the results show that variation between the two groups regarding the odds of making ethically sensitive decisions was significant, but at $90 \%$ confidence level. The results suggest that the more learners affirm that content of vignettes influences their ethical sensitivity in decision-making, the higher the odds that they will make ethically sensitive decisions and vice versa.

These results agree with the qualitative findings sourced through FGDs and KIIs. For instance, FGD participants noted that content of vignettes were key influencers of ethical sensitivity in decision-making, particularly in terms of the amount of information contained, and the ease of decoding and relating the information to real life experiences. In view of this, participants identified case studies, interviews and personal experiences as the primary contents for vignettes, which provided in-depth information that was easy to decipher, articulate and relate to ethical situations inherent in business and learning settings. In one instance, a participant observed that "...I prefer case studies because they provide clear information that helps me to understand real problems and make effective decisions that are acceptable to the concerned people." In view of this, participants proposed that vignettes formulated from case studies, interviews and personal experiences be integrated in business ethics training unit courses to enhance the effectiveness of experiential learning at the Department.

In addition, KII sessions revealed that most instructors use vignettes from case studies unwittingly. Participants indicated that some topics in the undergraduate syllabus for business education contain case narratives that enrich explanations of the concepts taught. Frequent users of case study vignettes observed that such resources enable learners to connect theoretical concepts to real life situations. Using the words of one instructor, "...case study vignettes are effective resources for experiential learning, particularly in this era of reality-based education, where learners need exposure to lived experiences. We also don't want to continue teaching abstract things; rather we are keen on provoking learners' imaginations using their own background knowledge and experiences, so that they become more effective interpreters of the world in which they live." The assertion implies that vignettes create a valuable linkage between the concepts taught in class or documented in books and lived experiences. Such linkage is essential for ethical sensitivity in decision-making.

Some participants noted that most learners find story vignettes interesting when applied during lessons, and they tend to remember such stories long afterwards. One participant illustrated the point by reciting a famous quote attributed to Confucius, "...tell me and I forget, teach me and I learn, involve me and I remember," in reference to the need to integrate story vignettes in business ethics lessons. Participants further indicated that when story vignettes revolve around ethical issues, learners tend to grasp essential virtues brought about by such stories. This makes story vignettes relevant for teaching business ethics.

\section{Summary, Discussions and Conclusions}

The content of vignettes included case study extracts, interviews, stories, textbook extracts, and personal experiences. Cumulatively, 102 (87.9\%) learners affirmed that the deployment of case study vignettes in business ethics lessons influenced their knowledge and ethical sensitivity in decision-making tendencies. This was followed by interview vignettes, which was affirmed by 96 (82.8\%) learners; textbook extract vignettes, 91 (78.4\%) learners; personal experiences, $90(77.6 \%)$ learners; while story vignettes were cited by $74(63.8 \%)$ learners. The findings suggest that case study vignettes influenced the highest proportion of learners' ethical sensitivity in decision-making, while story vignettes was cited by the least proportion of learners since learners found the case study vignettes more realistic than stories which are sometimes not anchored in their lived or imagined experience. On aggregate, the content of vignettes significantly correlated with ethical sensitivity in decisionmaking; leading to rejection of the null hypothesis for being inconsistent with the findings. More still, learners who agreed strongly that the content of vignettes influence their ethical sensitivity in decision-making had about 1.8 times the odds of making ethically sensitive decisions as their counterparts who disagreed strongly with the assertion. Besides, learners who agreed that the contents of vignettes influence their ethical sensitivity in decision-making were about 1.6 times as likely to make ethically sensitive decisions as their colleagues who indicated strong disagreement. In the first scenario, variation between the two groups was significant at $95 \%$ confidence level in terms of the odds of making ethically sensitive decisions; while in the second case, variation between the two groups was significant at $90 \%$ confidence level.

Furthermore, qualitative results showed that the content for vignettes and ethical sensitivity in decision-making were related, with case study vignettes, interview vignettes and vignettes extracted from personal experiences being the primary influencers of learners' ethical sensitivity in decision-making. The three content sources were cited because they provide detailed information that is not only easy to decode and articulate, but also easy to relate to real life ethical situations that learners can resonate with. More particularly, case study vignettes enable learners to connect theoretical concepts to real life situations. Case study vignettes also enable instructors to shift from teaching abstractions to provoking learners' imaginations, with the aim of making them effective interpreters of reality. In this regard, such vignettes create a valuable linkage between the concepts taught or documented in books and lived experiences, which is essential for experiential learning. Story vignettes were identified as common instructional 
resources at the Department, because they enable learners to pick essential virtues, which are elemental to ethical sensitivity and ethical decision-making.

Based on the findings of the study, influence of the content of vignettes on ethical sensitivity in decision-making was positive, meaning that the more the learners appreciated the relationship between vignette content and ethical sensitivity in decision-making, the stronger the odds that they will make ethically sensitive decisions and vice versa or that they will be able to identify the ethical issues presented by the content in the vignette. This calls for more sensitization of learners about the variety of possible contents for vignettes in order to improve knowledge and increase ethical sensitivity, both of which are crucial for ethical decision-making. A clear understanding of the sources of contents of vignettes is vital for ethical sensitivity in decision-making so that learners can be exposed to variety and not be limited to one for instance stories as is common at the Department. Training, facilitating and motivating instructors to apply vignettes consistently in business ethics course unit is likely to improve learners' knowledge of vignettes and even challenge them to develop some on their own and for their own teaching once they graduate. Equally important is the need to integrate outstanding vignette contents such as case study vignettes, interview vignettes and personal experience vignettes in the business ethics course unit.

Case study vignettes are known to provide rich, in-depth information that enhances learners' knowledge and skills, which are essential for developing ethical sensitivity among learners. With better knowledge and understanding, [37] observe that case study vignettes improve peer engagement and active participation in experiential teaching-learning of business ethics. Learners who are actively involved in learning processes become better retainers of knowledge and translators of such knowledge into action. Similarly, [11] identify case study vignettes as effective contents of vignettes that enhance ethical sensitivity in decision-making by learners. The importance of case study vignettes in experiential learning has also been amplified by [19] whose observation equate case study vignettes to useful stimuli for developing ethical sensitivity among learners. Consequently, the inclusion of case study vignettes as an instructional approach for the business ethics course unit is likely to improve ability of learners to make ethically sensitive decisions in their institutions and during the learning process.

Interviews also emerge as essential content source for vignettes in experiential teaching-learning of business ethics. Vignettes obtained from interviews with business leaders improve the effectiveness of experiential learning by helping learners to develop skills for breaking down complex scenarios into simple ethical issues that can be articulated and related to real life situations. Learners with such skills are better poised to make decisions that are ethically sensitive. As noted by [18], vignettes obtained through interviews with business practitioners equip learners with skills for stepwise analysis and discussion of ethical dilemmas, which is the process of making ethical decisions through simulations. Having been drawn from practical experiences of business practitioners, interview vignettes become an important component of instructional materials for enhancing learners' ability to make ethically sensitive decisions.

Personal experiences on particular aspects of business and instruction are also essential content of vignettes, which, in turn, equip learners with first-hand knowledge and skills for making ethical decisions. More particularly, vignettes drawn from personal experiences enable learners to gain knowledge and confidence for active participation in experiential learning sessions, which improves the ability to identify ethical issues and make ethically sensitive decisions. [37] affirm that personal experiences, together with accompanying discussion questions, are critical for inculcating moral sensitivity, invoking critical reflections and stimulating peer engagement among learners. As moral sensitivity and critical analysis improve, so does the ability of learners to make ethically sensitive decisions.

\section{Acknowledgements}

We thank the UoN for granting the first author the opportunity to pursue doctoral studies in Business Education, and for assigning the second and third authors as supervisors. We further thank the Department for permitting the first author to source information from their undergraduate learners. We remain indebted to all the participants who provided the requisite information. Lastly, we thank Thomas Oriwo, Tom Odhiambo and Noah Oyembo for providing research assistance.

\section{References}

[1] Allibaih, M., \& Khan, L. M. (2015). Weaving Together Peer Assessment, Audios and Medical Vignettes in Teaching Medical Terms. International Journal of Medical Education, $6,172-178$.

[2] Assudani, R. H., Manolis, C., Burns, D. J., \& Chinta, R. (2011). The Effect of Pedagogy on Students' Perceptions of the Importance of Ethics and Social Responsibility in Business Firms. Ethics \& Behaviour, 21 (2), 103-117.

[3] Badua, F., Sharifi, M., \& Mediavilla, F. M. (2014). What Makes a Top-Selling Textbook? Comparing Characteristics of AIS Textbooks. Journal of Education for Business, 89 (5), 257-262.

[4] Beard, C. (2010). The Experiential Learning Toolkit: Blending Practice with Concepts. Kogan Page Publishers.

[5] Best, J. W., \& Kahn, J. V. (2016). Research in Education (10th ed.). Pearson India.

[6] Bryman, A., \& Cramer, D. (1997). Quantitative Data Analysis with SPSS for Windows: A Guide for Social Scientists. Routledge.

[7] Campbell, M., \& Zegwaard, K. E. (2011). Values, ethics and empowering the self through cooperative education. Asia Pacific Journal of Cooperative Education, 12 (3), 205-216. 
[8] Carroll, A. B. (1990). Principles of Business Ethics: Their Role in Decision Making and an Initial Consensus. Management Decision, 28
https://doi.org/10.1108/00251749010006032.

[9] Cochran, W. G. (1977). Sampling techniques. John Wiley \& Sons.

https://www.cabdirect.org/cabdirect/abstract/19562201087.

[10] Cull, M., \& Sloan, T. (2016). Characteristics of Trust in Personal Financial Planning. Financial Planning Research Journal, 2 (1), 12-35.

[11] Dagar, V., \& Yadav, A. (2016). Constructivism: A Paradigm for Teaching and Learning. Arts and Social Sciences Journal, 7. https://doi.org/10.4172/2151-6200.1000200.

[12] Davis, S., DeZoort, F. T., \& Kopp, L. S. (2006). The Effect of Obedience Pressure and Perceived Responsibility on Management Accountants' Creation of Budgetary Slack. Behavioral Research in Accounting, 18 (1), 19-35. https://doi.org/10.2308/bria.2006.18.1.19.

[13] Dench, S., Iphofen, R., \& Huws, U. (2004). An EU Code of Ethics for Socio-Economic Research. Institute for Employment Studies.

[14] Effelsberg, D., Solga, M., \& Gurt, J. (2014). Transformational Leadership and Follower's Unethical Behavior for the Benefit of the Company: A Two-Study Investigation. Journal of Business Ethics, 120 (1), 81-93. https://doi.org/10.1007/s10551-013-1644-z.

[15] Emanuel, V., \& Cross, V. (2012). Using Vignettes to Teach Stroke Care. Nursing Times, 108 (9), 20-22. PubMed.

[16] Freeman, R. E., Dunham, L., Fairchild, G., \& Parmar, B. (2015). Leveraging the Creative Arts in Business Ethics Teaching. Journal of Business Ethics, 131 (3), 519-526. https://doi.org/10.1007/s10551-014-2479-y.

[17] Gray, D., Griffin, C., \& Nasta, T. (2005). Training to Teach in Further and Adult Education (2nd edn). http://epubs.surrey.ac.uk/816101/.

[18] Harland, T. (2014). Learning About Case Study Methodology to Research Higher Education. Higher Education Research \& Development, 33 (6), 1113-1122. https://doi.org/10.1080/07294360.2014.911253.

[19] Hughes, R., \& Huby, M. (2002). The Application of Vignettes in Social and Nursing Research. Journal of Advanced Nursing, $37, \quad 382-386 . \quad$ https://doi.org/10.1046/j.13652648.2002.02100.x.

[20] Ismail, S., \& Mohd Ghazali, N. A. (2011). Ethical Ideology and Ethical Judgments of Accounting Practitioners in Malaysia. Gadjah Mada International Journal of Business, 13 (2), 107. https://doi.org/10.22146/gamaijb.5486.

[21] Jonson, E. P., McGuire, L. M., \& O’Neill, D. (2015). Teaching Ethics to Undergraduate Business Students in Australia: Comparison of Integrated and Stand-Alone Approaches. Journal of Business Ethics, 132 (2), 477-491.

[22] Kidwell, R. E., \& Valentine, S. R. (2009). Positive Group Context, Work Attitudes, and Organizational Misbehavior: The Case of Withholding Job Effort. Journal of Business Ethics, 86 (1), 15-28. https://doi.org/10.1007/s10551-0089790-4.
[23] Kolb, A. Y., \& Kolb, D. A. (2017). Experiential Learning Theory as a Guide for Experiential Educators in Higher Education. A Journal for Engaged Educators, 1 (1), 7-44.

[24] Koleva, S. P., Graham, J., Iyer, R., Ditto, P. H., \& Haidt, J. (2012). Tracing the Threads: How Five Moral Concerns Help Explain Culture War Attitudes. Journal of Research in Personality, $46 \quad$ (2), 184-194. https://doi.org/10.1016/j.jrp.2012.01.006.

[25] Manolis, C., Burns, D. J., Assudani, R., \& Chinta, R. (2013). Assessing Experiential Learning Styles: A Methodological Reconstruction and Validation of the Kolb Learning Style Inventory. Learning and Individual Differences, 23, 44-52. https://doi.org/10.1016/j.lindif.2012.10.009.

[26] Massoudi, M. (2010). Learning and Teaching Ethics through Stories: A Few Examples from the Buddhist Tradition. Creative Education, 01 (01), 18-24. https://doi.org/10.4236/ce.2010.11004.

[27] Mazanec, J. A. (2005). New Methodology for Analyzing Competitive Positions: A Demonstration Study of Travelers' Attitudes Toward Their Modes of Transport. Tourism Analysis, 9 (1). https://doi.org/info:doi/10.3727/108354205789807283.

[28] McDonald, R. (2015). Leveraging Change by Learning to Work with the Wisdom in the Room: Educating for Responsibility as a Collaborative Learning Model. Journal of Business Ethics, 131 (3), 511-518. https://doi.org/10.1007/s10551-014-2477-0.

[29] McGee, R. W. (2011). The Ethics of Tax Evasion: Perspectives in Theory and Practice. Springer Science \& Business Media.

[30] McLeod, S. (2017). Kolb's Learning Styles and Experiential Learning Cycle | Simply Psychology. https://www.simplypsychology.org/learning-kolb.html.

[31] Miller, A., Shoptaugh, C., \& Wooldridge, J. (2011). Reasons Not to Cheat, Academic-Integrity Responsibility, and Frequency of Cheating. The Journal of Experimental Education, $\quad 79 \quad$ (2), 169-184. https://doi.org/10.1080/00220970903567830.

[32] Morrison, R. L., Stettler, K., \& Anderson, A. E. (2004). Using Vignettes in Cognitive Research on Establishment Surveys. Journal of Official Statistics, 20 (2), 319-340.

[33] Myers, J. L., Well, A., \& Lorch, R. F. (2010). Research Design and Statistical Analysis. Routledge.

[34] Nachmias, C. F., \& Nachmias, D. (1996). Research Methods in the Social Sciences. St. Martin's Press.

[35] Odundo, P. A., \& Gunga, S. O. (2013). Effects Of Application Of Instructional Methods On Learner Achievement In Business Studies In Secondary Schools In Kenya. International Journal of Education and Research, 1 (5), 1-22.

[36] Oluoch, P. M., Odundo, P. A., \& Mwangi, J. (2019). Value of Vignette Contexts in Ethical Decision Making Among Business Education Students at the University of Nairobi. Imperial Journal of Interdisciplinary Researcg (IJIR), 5 (2), 66-76.

[37] Oluoch, P. M., Odundo, P. A., Mwangi, J., \& Oyier, C. R. (2018). Types of Vignettes and Ethical Decision-Making among Business Education Students. International Journal of Business and Management, 13 (10), 249. https://doi.org/10.5539/ijbm.v13n10p249. 
[38] Omwenga, E. I. (2006). Pedagogical Issues and E-learning Cases: Integrating ICTs into Teaching and Learning process. Nairobi: School of Computing and Informatics, 11.

[39] Pan, Y., \& Sparks, J. R. (2012). Predictors, Consequence, and Measurement of Ethical Judgments: Review and MetaAnalysis. Journal of Business Research, 65 (1), 84-91. https://doi.org/10.1016/j.jbusres.2011.02.002.

[40] Petocz, P., \& Dixon, P. (2011). Sustainability and Ethics: Graduate Dispositions in Business Education. Asian Social Science, 7 (4), 18-25. https://doi.org/10.5539/ass.v7n4p18.

[41] Petrina, S. (2004). Curriculum and Instruction for Technology Teachers. Online: Http://Www. Cust. Educ. Ubc. ca/Programs/Tsed/Research/Books.

[42] Qualters, D. M. (Ed.). (2010). Bringing the Outside in: Assessing Experiential Education: New Directions for Teaching and Learning. In C. Wehlburg, Experiential Education: Making the Most of Learning Outside the Classroom (pp. 55-62). John Wiley \& Sons.
[43] Rindfleisch, A., Malter, A. J., Ganesan, S., \& Moorman, C. (2008). Cross-Sectional Versus Longitudinal Survey Research: Concepts, Findings, and Guidelines: Journal of Marketing Research, 45 (3), 1-23. https://doi.org/10.1509/jmkr.45.3.261.

[44] Sarfo, F. K. (2007). Educational Technology Accra (K. I. Adentwi, Ed.). Wilas press.

[45] Stedham, Y., \& Beekun, R. I. (2013). Ethical Judgment in Business: Culture and Differential Perceptions of Justice Among Italians and Germans. Business Ethics: A European Review, 22 (2), 189-201. https://doi.org/10.1111/beer.12018.

[46] University of Nairobi Annual Report 2018. (2018). University of Nairobi. http://erepository.uonbi.ac.ke/handle/11295/106525.

[47] Weiss, J. W. (2014). Business Ethics: A Stakeholder and Issues Management Approach (6th ed.). Berrett-Koehler Publishers.

[48] Wuensch, K. L. (2010). Logistic Regression with SPSS, 2006. $\mathrm{http} / / /$ core.ecu.edu/psyc/wuenschk/spss/logistic.sav. 